\title{
Development of antimicrobial biomaterials produced from chitin-nanofiber sheet/silver nanoparticle composites
}

Vinh Quang Nguyen ${ }^{1,2}$, Masayuki Ishihara ${ }^{2 *}$, Jun Kinoda ${ }^{3}$, Hidemi Hattori ${ }^{2}$, Shingo Nakamura ${ }^{2}$, Takeshi Ono ${ }^{4}$, Yasushi Miyahira ${ }^{4}$ and Takemi Matsui ${ }^{1}$

\begin{abstract}
Background: Chitin nanofibers sheets (CNFSs) with nanoscale fiber-like surface structures are nontoxic and biodegradable biomaterials with large surface-to-mass ratio. CNFSs are widely applied as biomedical materials such as a functional wound dressing. This study aimed to develop antimicrobial biomaterials made up of CNFS-immobilized silver nanoparticles (CNFS/Ag NPs).
\end{abstract}

Materials and methods: CNFSs were immersed in suspensions of Ag NPs (5.17 $\pm 1.9 \mathrm{~nm}$ in diameter; mean \pm SD) for $30 \mathrm{~min}$ at room temperature to produce CNFS/Ag NPs. CNFS/Ag NPs were characterized by transmission electron microscopy (TEM) and then tested for antimicrobial activities against Escherichia (E.) coli, Pseudomonas $(P$.$) aeruginosa, and \mathrm{H} 1 \mathrm{~N} 1$ influenza $\mathrm{A}$ virus, three pathogens that represent the most widespread infectious bacteria and viruses. Ultrathin sectioning of bacterial cells also was carried out to observe the bactericidal mechanism of Ag NPs.

Results: The TEM images indicated that the Ag NPs are dispersed and tightly adsorbed onto CNFSs. Although CNFSs alone have only weak antimicrobial activity, CNFS/Ag NPs showed much stronger antimicrobial properties against E. coli, P. aeruginosa, and influenza A virus, with the amount of immobilized Ag NPs onto CNFSs.

Conclusions: Our results suggest that CNFS/Ag NPs interacting with those microbes exhibit stronger antimicrobial activities, and that it is possible to apply CNFS/Ag NPs as anti-virus sheets as well as anti-infectious wound dressings.

Keywords: Antimicrobial biomaterials, Chitin nanofiber sheets, Silver nanoparticles, Wound dressings, Anti-virus sheets

\section{Background}

Chitin/chitosan is second most abundant natural nontoxic biomaterial, and is produced from the exoskeleton of sea food, shellfish, crabs, shrimps, insects, edible mushrooms, and sea weed algae [1]. The advantages in biochemical activities of chitin/chitosan-based materials include: antiinfectious activity [2]; stimulation of angiogenesis/wound repair; and stabilization/activation of growth factors [3-7]. Since chitin nanofiber sheets (CNFSs) are biodegradable and exhibit large surface-to-mass ratios, CNFSs are widely

\footnotetext{
* Correspondence: ishihara@ndmc.ac.jp

${ }^{2}$ Research Institute, National Defense Medical College, 3-2 Namiki, Tokorozawa, Saitama 359-1324, Japan

Full list of author information is available at the end of the article
}

applied in pharmaceuticals as composite materials. The favorable properties of CNFS-based materials are enhanced as sizes of their fibers are decreased across the range of 1-100 nm [8]. In case of cosmetic dermatology, chitin nanofibrils do not only protect corneocytes and intracorneal lamellae, but also helping to maintain cutaneous homeostasis. In addition, CNFSs neutralize the activity of free radicals and trap them in their structure, thereby regulating correct cell turnover [9]. The positive charges on the surface of the fibers, along with the chelating capacity of the acetamido groups of the chitin/chitosan molecule, play important roles in adsorption of heavy metals $[10,11]$. Our previous study demonstrated that chitin powder with nanoscale fiber-like surface structures can adsorb Ag NPs more 
efficiently than chitin powder with flat/smooth film-like surface structures [12]. CNFSs have attracted much attention for application as components of pharmaceutics such as drug carriers, textile materials, sutures, and scaffold materials for tissue engineering [13,14].

Ag NPs have strong antimicrobial activity against most microorganisms, including bacteria, fungi, and viruses. In recent publications, we demonstrated that chitin/chitosan/Ag NP composites have enhanced antimicrobial activities against microbial pathogens, including bacteria ( $E$. coli), fungi (Aspergillus niger), and virus (H1N1 influenza A virus) [15-17]. The bactericidal activity of Ag NPs is believed to result from Ag NP interactions with the cell wall, permitting Ag NPs to penetrate the membrane, thereby leading to the cell death [18]. In addition, silver ions released from Ag NP surface are thought to bind to sulfhydryl groups, leading to protein denaturation [19]. Furthermore, silver ions have been shown to penetrate through ion channels without causing damage to the cell membranes, where the ions denature the ribosome and suppress the expression of enzymes and proteins essential to ATP production [20]. Silver ions can interact with the bases in DNA causing loss of replication [21,22]. Ag NPs also induce the formation of free radicals, which in turn damage the membrane and cause cell death, formation of bactericidal reactive oxygen species (ROS), and lactate dehydrogenase activity involved in the respiratory chain [23]. Bacterial DNA can be affected by ROS, resulting in the production of superoxide anion $\left(\mathrm{O}_{2}^{-}\right)$, hydroxyl radical $(\mathrm{OH})$, and singlet oxygen $\left({ }^{1} \mathrm{O}_{2}\right)$ with subsequent oxidative damage [23,24].

Questions have been raised about the safety of prolonged use of Ag NPs in humans and animals. Generally, silver does not adversely affect mammalian cell viability. Hence, silver has been incorporated into various materials and used in antimicrobial materials to protect from infectious contamination [25]. Recently, in vitro studies in human cells have reported that Ag NP exposure induces metabolic arrest rather than cell death, and that human cells have a greater resistance to the toxic effects of Ag NPs in comparison with those from other organisms [26,27]. Furthermore, previous studies have revealed that while Ag NP-containing chitosan-based wound dressings are cytotoxic in vitro, such wound dressings perform satisfactorily in vivo [28]. The aim of the present work is to evaluate the bactericidal (against E. coli and P. aeruginosa) and antiviral (against influenza virus H1N1) activities of CNFS/Ag NPs, for potential biomedical applications such as wound dressings and antivirus sheets.

\section{Results}

\section{Characterization of Ag NPs and CNFS/Ag NPs}

$\mathrm{Ag}$ NPs were synthesized by autoclaving (at $121^{\circ} \mathrm{C}$ and 20 $\mathrm{kPa}$ ) a mixture of only three components: silver-containing glass powder, glucose, and water [17,29]. TEM images showed that the Ag NPs were spherical with the average particle size of $5.17 \pm 1.92 \mathrm{~nm}$ (mean $\pm \mathrm{SD})$. The results of UV-Vis analysis of the Ag NPs suspension revealed that the peak at $390.5 \mathrm{~nm}$ is representative of the Ag NPs in this study (Figure 1).

The surface morphology of the CNFS has been characterized using SEM imaging. The CNFS has a nanoscale fiber-like surface structure (Figure 2A). TEM observation of CNFS/Ag NPs revealed that the Ag NPs were stably adsorbed to the surface of CNFS (Figure 2B). Based on comparison of absorbance values of Ag NP suspension before and after reaction with CNFS, along with the equation for the standard curve of absorbance at $390.5 \mathrm{~nm}$ as a
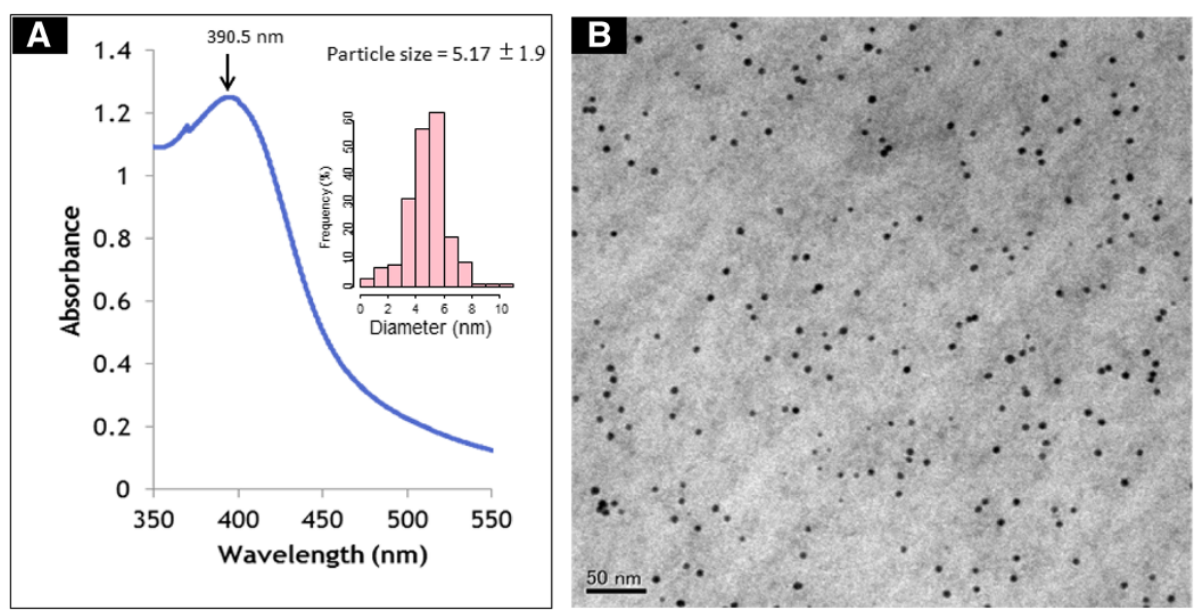

Figure 1 Absorption of Ag NPs to ANSF. (A) The UV-visible absorption spectrum of Ag NPs. The peak of absorbance at the wavelength of $390.5 \mathrm{~nm}$ is indicated. The inset figure is the particle size distribution histogram of the Ag NPs. (B) TEM micrograph of Ag NPs. Scale bar represents $50 \mathrm{~nm}$. 

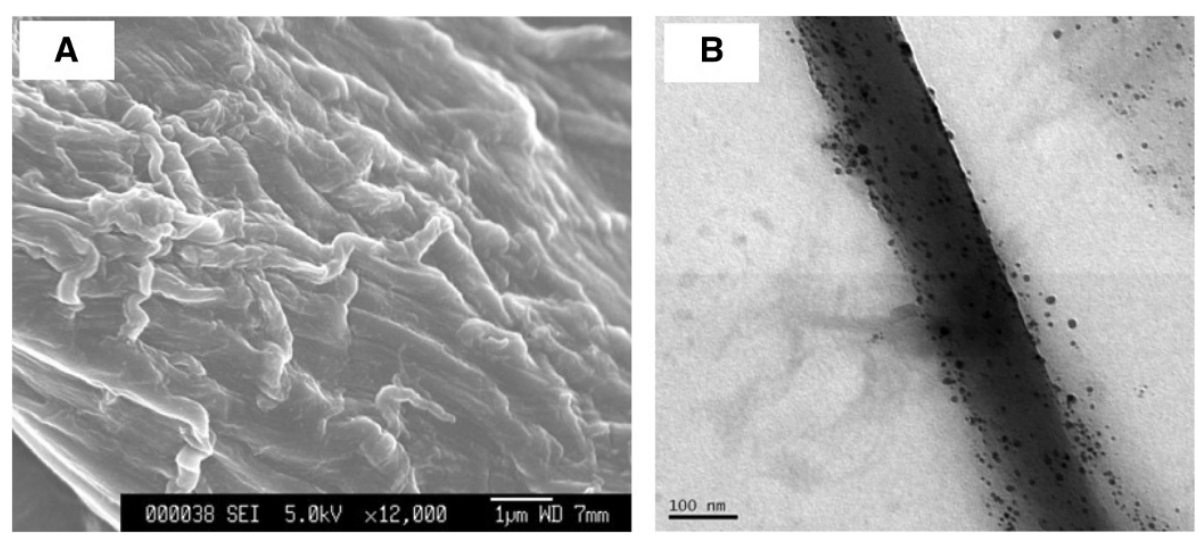

Figure 2 SEM and TEM images of CNFS. SEM image of CNFS; scale bar represents $1 \mu \mathrm{m}$ (A). TEM image of CNFS/Ag NPs composite sheet; scale bar represents $100 \mathrm{~nm}$ (B).

function of the concentration of Ag NPs in suspension, we estimated that Ag NPs were immobilized on CNFS at 8. $45 \mu \mathrm{g}$ per $\mathrm{cm}^{2}$ (Figure 3A and Figure 3B).

\section{Bactericidal activity of CNFS/Ag NPs}

To establish the bactericidal properties of CNFS/Ag NPs, the sheet were tested with two infectious bacteria: $E$. coli and $P$. aeruginosa. The inhibition zone of bacterial growth around CNFS/Ag NPs and CNFS alone against E. coli and $P$. aeruginosa are shown in Figure 4. There was no zone of growth inhibition around CNFS alone for either $E$. coli or P. aeruginosa. With CNFS/Ag NPs $(8.5 \mu \mathrm{g} / \mathrm{ml})$, there were clear zones of inhibition of $\approx 30 \mathrm{~mm}$ diameter (for E. coli) and $\approx 25 \mathrm{~mm}$ diameter (for P. aeruginosa) around CNFS/ Ag NPs after $24 \mathrm{~h}$ incubation (Figure 4).

Bactericidal tests of CNFS/Ag NPs were performed against $E$. coli and $P$. aeruginosa by counting the viable bacterial colonies after treatment with different concentrations of $\mathrm{Ag}$ NPs immobilized on CNFS (2.3, 3.8, $8.5 \mu \mathrm{g} / 1 \mathrm{~cm}^{2}$ CNFS). Samples of E. coli were completely eradicated when exposed to CNFS contained $8.5 \mu \mathrm{g} / \mathrm{ml}$ of Ag NPs. The high concentration Ag NPs immobilized on CNFS gave significant decreases of cell number in log $10 \mathrm{CFU} / \mathrm{ml}$, while CNFS alone gave only a little decrease against $E$. coli and $P$. aeruginosa. Thus, the bactericidal activity of CNFS/Ag NPs increased with increased Ag NP loading (Figure 5).

\section{Antiviral activity of CNFS/Ag NPs}

In order to confirm the antiviral activity of CNFS/Ag NPs, the CNFSs carrying various amounts of immobilized Ag NPs were evaluated for antiviral activity for human influenza A virus (A/PR/8/34 (H1N1)). The high concentration Ag NPs immobilized on CNFS gave significant decreases
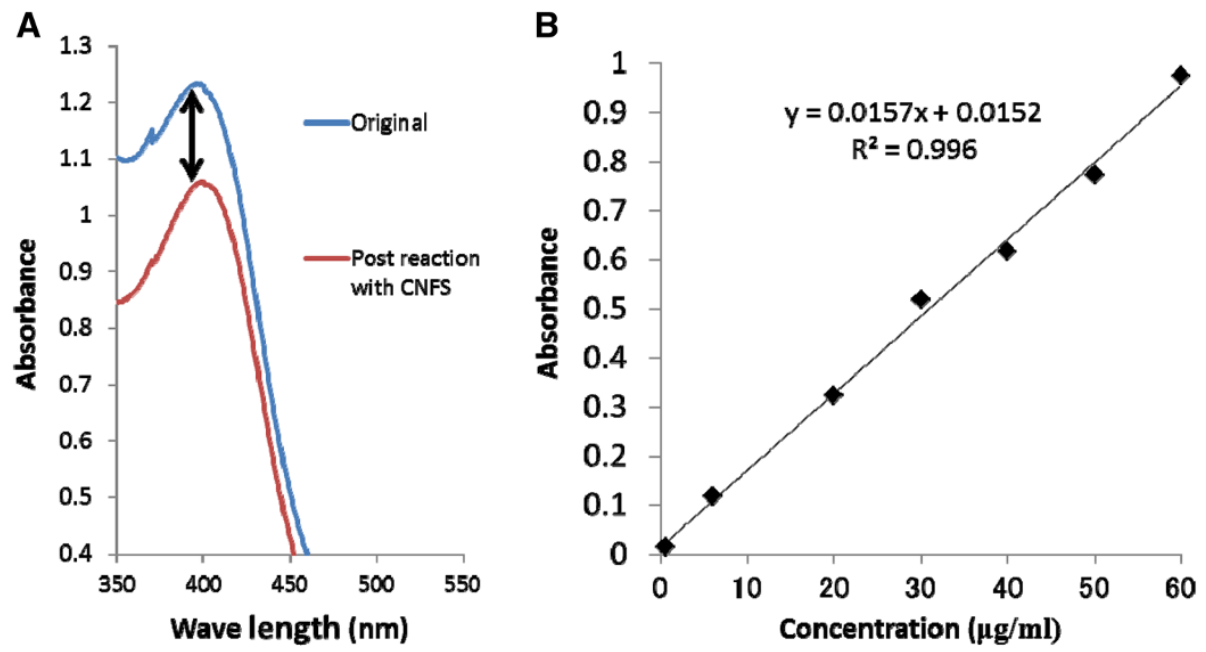

Figure 3 The absorbance spectra of Ag NPs. The absorbance spectra of original Ag NP suspension (blue line) and suspension after reaction with $1 \mathrm{~cm}^{2}$ CNFS (red line) (A). The relationship between absorbance at $390.5 \mathrm{~nm}$ and the concentration of Ag NPs in the suspension (B). 

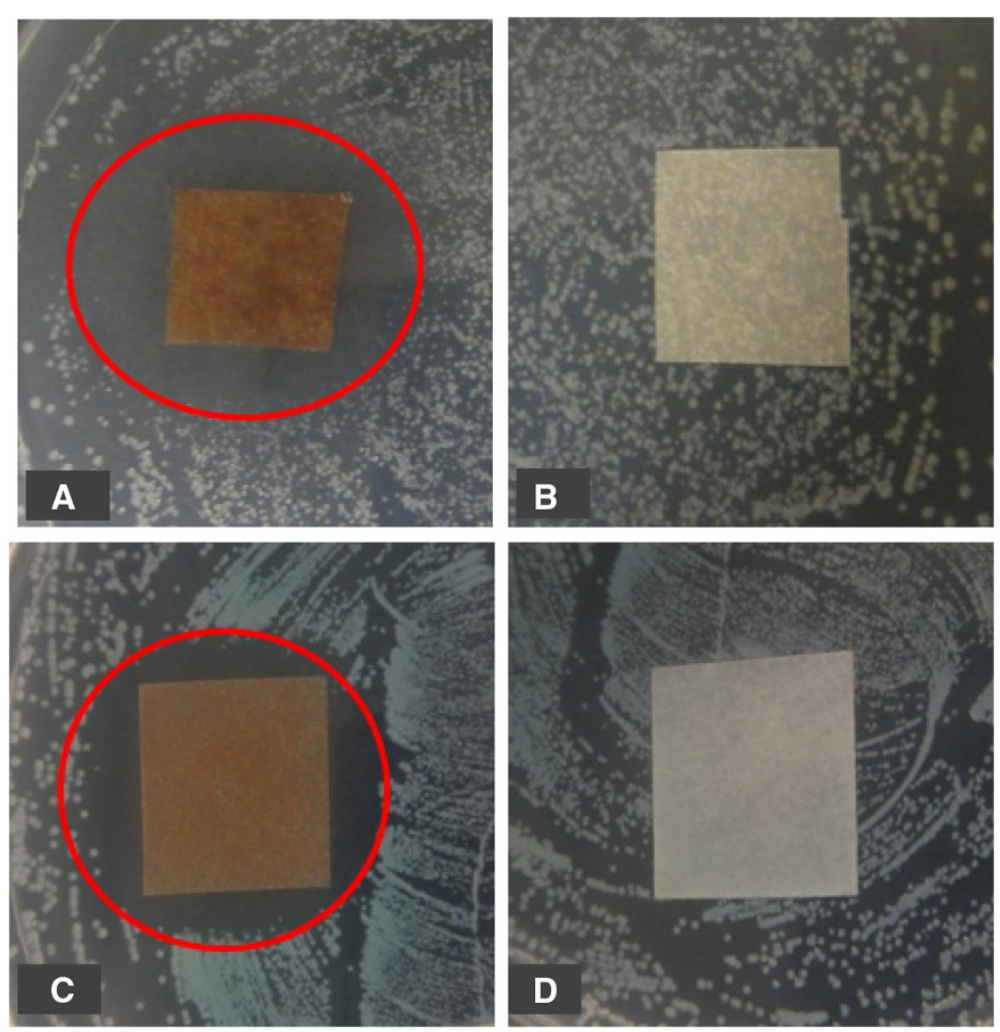

Figure 4 Antimicrobial activity of CNFS/Ag NPs against $E$. coli (A); CNFS alone against E. coli (B); CNFS/Ag NPs against $P$. aeruginosa (C); and CNFS alone against $P$. aeruginosa (D). The CNFS/Ag NPs showed inhibition zone of bacterial growth as shown with red circles (A and C), although the CNFS alone exhibited no detectable inhibitory activity against either bacterial species (B and D).

of virus number in $\log 10 \mathrm{CFU} / \mathrm{ml}$, while CNFS alone gave only a little decrease against influenza A virus. At concentration of Ag NPs of $8.5 \mu \mathrm{g} / 1 \mathrm{~cm}^{2}$ chitin sheet, there was a reduction of greater than $2 \log 10$ (100-fold) corresponding to reduction of viral titers by approximate 99\% (Figure 6). This mentions that the antiviral activities of the CNFS/Ag NPs sheet were due to the interaction between virions and Ag NPs. The viruses may be adsorbed and immobilized on the CNFS/Ag NPs sheet. Therefore, inceasing amount of $\mathrm{nAg}$ on the chitin sheet makes more viruses adsored and immobilized on the CNFS/Ag NPs sheet.

\section{Ultrathin sectioning of bacterial cells}

The mechanism(s) of bactericidal activity of Ag NPs remain poorly understood. Ultrathin sectioning was carried out to obtain further understanding of the bactericidality and the interaction of the Ag NPs with bacterial cells. After $1 \mathrm{~h}$ treatment with a suspension of Ag NPs, the cytoplasmic components of E. coli and P. aeruginosa were coagulated, leading to vacant spaces within the cells. Gross inspection of the TEM images revealed non-homogeneity of the cytoplasm in the Ag NP-treated cells compared with the controls (Figure 7). The density of cytoplasmic components in treated cells was obviously decreased compared with the control. Plasma membranes of treated cells were detached from the cell wall, leaving open spaces between the membrane and cell wall. Furthermore, DNA was condensed (Figure 7).

\section{Discussion}

Several kinds of materials are used for wound dressings, including cotton, chitin, chitosan, alloskin, pigskin, and other biologic-based materials. The various materials are commonly used in clinical settings, but these dressings often have some disadvantages such as low antimicrobial activity, allergenicity, toxic effects, and poor adhesiveness [8-10]. In the present study, we developed a potential wound dressing composed of Ag NPs $(5.17 \pm 1.9 \mathrm{~nm}$ in diameter) immobilized on CNFS to remedy some of the disadvantages of current wound dressings. CNFS was combined with Ag NPs, which act as a barrier to microorganisms, thereby limiting cross contamination. The Ag NPs were homogeneously dispersed and tightly immobilized on CNFS. The CNFS/Ag NPs showed strong antimicrobial activity against $E$. coli, $P$. aeruginosa, and influenza A virus.

The Ag NPs used in this research were produced using environmental-friendly materials and processes to control the size of Ag NPs, yielding Ag NPs of $\approx 5 \mathrm{~nm}$ in diameter. Components of the NPs included silver-containing glass 

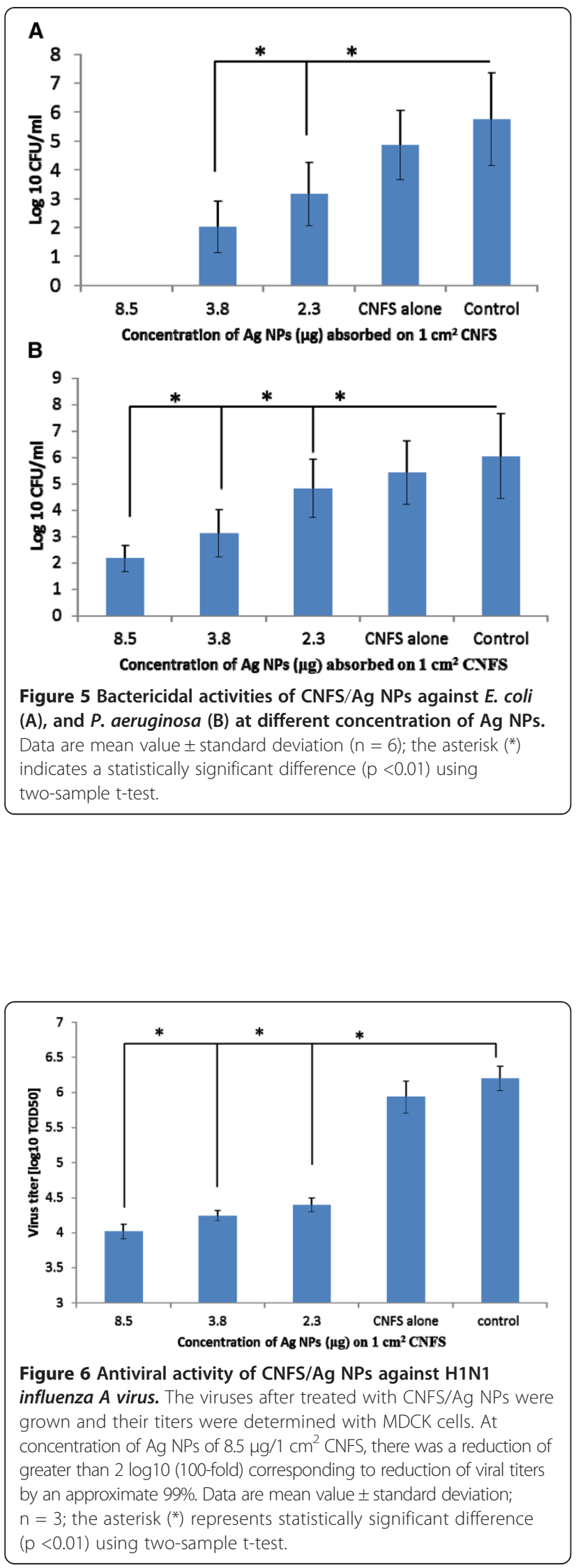

powder, glucose, and water. Silver-containing glass powder often is used in osteal or dental applications as an antimicrobial agent; glucose has the advantage of being an environmentally friendly agent [29]. In previous work, we have demonstrated that the antimicrobial activity of $\mathrm{Ag}$ NPs depended on particle size $[12,15,17]$. Ag NPs of small size (3-10 nm diameter) have strong antimicrobial activity against $E$. coli, $P$. aeruginosa, and influenza A virus, and it is hypothesized that Ag NPs with smaller particle sizes have larger available surface areas for interaction with microorganisms [17,29].

The CNFS used in this study has a nanoscale fiberlike surface structure, with corresponding increases in the available surface area for adsorption of Ag NPs. In addition, the advantages in biochemical activities of chitin/ chitosan-based materials include anti-infectious activity [2], stimulation of angiogenesis/wound repair, and stabilization/ activation of growth factors [3-7]. Recent studies show that the application of CNFS to skin improved the epithelial granular layer and increased granular density, suggesting the potential use of CNFS as a component of skin-protective formulations [30]. CNFS also has been shown to inhibit mucosal inflammation by suppressing the MPO-positive cells such as leukocytes [31].

This study used CNFS, a commercially available wound dressing, in combination with Ag NPs to provide stronger antimicrobial ability. The composite thus might serve as a new biocompatible wound dressing with reduced danger of cross contamination. CNFS/Ag NPs showed much stronger bactericidal activity against $E$. coli and $P$. aeruginosa, with clear zones of inhibition around the sheet. We also observed antiviral activity against influenza A virus, presumably due to the interaction between virions and Ag NPs immobilized on CNFS. Therefore, increasing amounts of Ag NPs on CNFS may further increase the number of virions immobilized on CNFS/Ag NPs, yielding increased virucidal activity. Our results suggest that CNFS/Ag NPs can be applied not only as functional wound dressings, but also as antimicrobial agents, including antivirus sheets.

CNFSs containing $8.5 \mu \mathrm{gg} \mathrm{NPs} / 1 \mathrm{~cm}^{2}$ sheet $(7.3 \pm$ $0.1 \mathrm{mg}$ ) completely eradicated $E$. coli. Several potential mechanisms have been reported for the bactericidal activities of Ag NPs [21,22]. Those studies showed that Ag NP exposure resulted in decreased density of cytoplasmic components, condensation of bacterial DNA, and disorganization of the cytoplasmic membrane with detachment of the plasma membrane from the cell wall. These phenomena suggested that Ag NPs induced a loss of integrity of the cytoplasm and membranes, causing malfunction of organelles and membranes, and leading to cell death. Alternatively, bacterial DNA could be affected by ROS, resulting in the production of superoxide anions $\left(\mathrm{O}_{2}{ }^{-}\right)$with subsequent oxidative damage [23]. This study is required to carry out biochemical analyses to confirm those mechanism. 

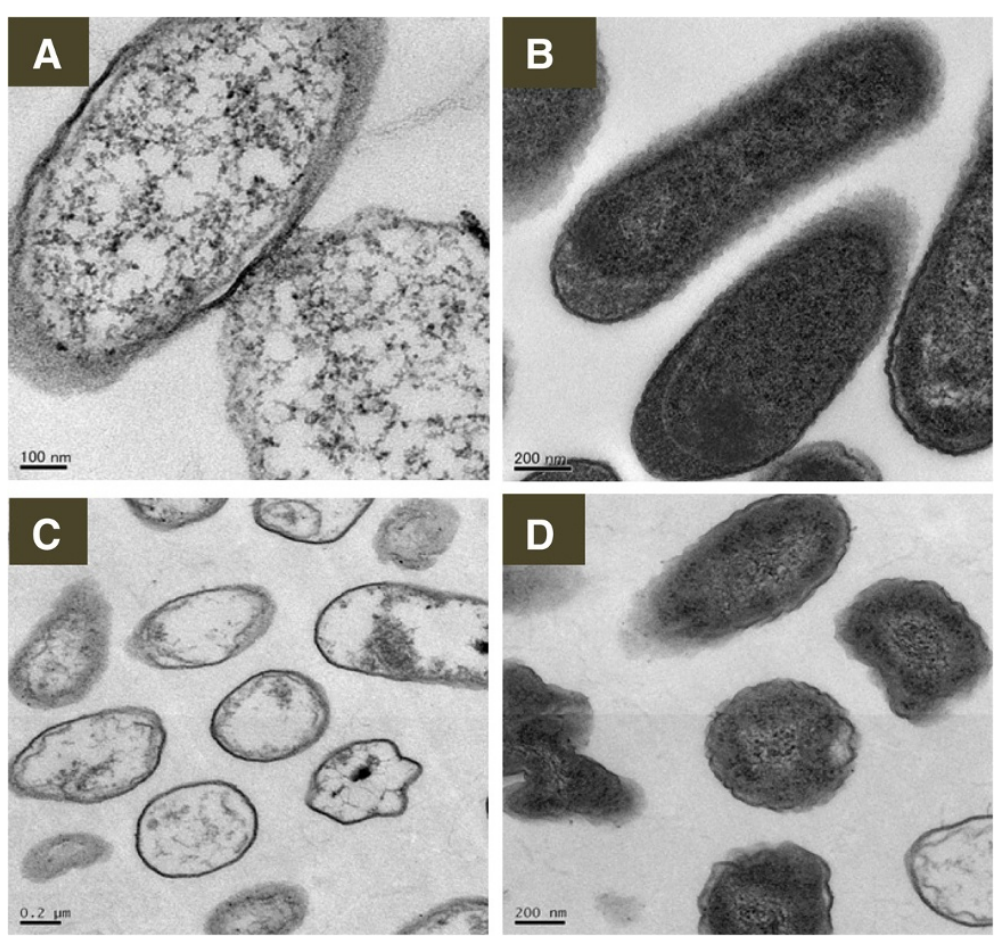

Figure 7 Representative TEM images of morphology and structure of E. coli and P. aeruginosa. (A) E. coli treated with Ag NPs; (B) normal E. coli; (C) P. aeruginosa treated with Ag NPs; (D) normal P. aeruginosa. Exposure to Ag NPs resulted in damage to the structure of bacterial cell membranes, condensed DNA, and coagulated cytoplasmic components. Normal bacterial cells were smooth, exhibiting intact surfaces and undamaged structures of inner membranes. Scale bars are as indicated.

The effect of the size of Ag NPs on antiviral activity suggests that various viruses interact selectively with smaller $(\leq 10 \mathrm{~nm}$ diameter) $\mathrm{Ag}$ NPs, as previously reported for HIV-1 [32] and hepatitis B viruses [33]. We also previously reported a size-dependence for the effect of free Ag NPs on antiviral activity against influenza A virus [29]. In the context of anti-influenza A virus activity, further spatial restriction due to the CNFS would be expected to prevent or weaken the interaction between virions and $\mathrm{Ag}$ NPs. Although the virus was not completely eradicated when exposed to CNFS/Ag NPs, the adsorption of $\mathrm{Ag}$ NPs onto CNFS provided stronger antivirus activity. Thus, the interaction between the virions and the $\mathrm{Ag}$ NPs is expected to be further increased with increasing amounts of Ag NPs on the CNFSs.

\section{Conclusions}

Our TEM image analysis indicated that Ag NPs are dispersed and tightly adsorbed on CNFS. Our antimicrobial assays further demonstrated that Ag NPs immobilized on CNFS provide much higher antimicrobial activities against $E$. coli, $P$. aeruginosa, and influenza A virus. Thus, we propose that CNFS/Ag NPs might find use as antiinfluenza sheets as well as anti-bacterial wound dressing sheets.

\section{Materials and methods \\ Materials}

Silver-containing glass powder (BSP21, Ag content: $1 \mathrm{wt} \%$; average grain size: $10 \mu \mathrm{m})$ was purchased from Kankyo Science (Kyoto, Japan). CNFSs (degree of deacetylation: $\approx 30 \%$ ) used in this study were obtained as the commercial product (BeschitinW, Unichika Ltd., Tokyo, Japan). D-Glucose was purchased from Wako Pure Chemical Industries, Ltd. (Osaka, Japan). All chemicals were used as received.

\section{Preparation of Ag NPs}

A suspension of size-controlled Ag NPs was prepared as previously described [29]. Briefly, $0.5 \mathrm{~g}$ of Ag-containing glass powder was dispersed in $50 \mathrm{ml}$ of an aqueous solution of $0.8 \mathrm{wt} \%$ glucose in a $100 \mathrm{ml}$ glass vial. The mixture was autoclaved at $121^{\circ} \mathrm{C}$ and $200 \mathrm{kPa}$ for $20 \mathrm{~min}$ and then gradually cooled to room temperature; the mixture then was centrifuged at $1500 \mathrm{~g}$ for $10 \mathrm{~min}$. The resulting brown supernatant containing the Ag NP suspension was stored in the dark at $4{ }^{\circ} \mathrm{C}$. Transmission electron microscopy (TEM) specimens were prepared by casting a small drop of a suspension of Ag NPs onto a carbon-coated copper grid; excess solution was then removed using filter paper and the specimens were dried at room temperature. TEM images were obtained using a JEOL JEM-1010 microscope 
(Nihon Electronics Inc., Tokyo, Japan) operated at $80 \mathrm{kV}$. The diameter size of Ag NPs from TEM image was determined using ImageJ 1.45 software (http://rsb.info.nih.gov/ij).

\section{Preparation of CNFS/Ag NPs}

CNFS $(1 \mathrm{~cm} \times 1 \mathrm{~cm})$ was submerged in a $1.5 \mathrm{ml}$ ClickFit polypropylene microcentrifuge tube (TreffLab AG, Degersheim, Switzerland) containing $1 \mathrm{ml}$ of Ag NP suspension (at about $30 \mu \mathrm{g} / \mathrm{ml}$ ) and shaken well for $30 \mathrm{~min}$ using a shaker (Mild Mixer PR-36; TAITEC, Tokyo, Japan). The post-reaction supernatant was analyzed using a UV-visible spectrometer (Jasco V-630, Tokyo, Japan) to measure the amount of unreacted Ag NPs as a peak of absorbance at wavelength of $390.5 \mathrm{~nm}$. The CNFS/Ag NP composites were washed twice with distilled water. The washed composites were air dried up on a clean bench for $1 \mathrm{~h}$ and used in bactericidal assays on the same day. TEM inspection confirmed that the Ag NPs were homogeneously dispersed and immobilized on the CNFS, which had become brown in color. The concentrations of Ag NPs immobilized on the CNFS were calculated based on the UV-Vis spectra of Ag NPs before and after mixing with CNFS, using a standard curve of Ag NPs generated for a previous publication [15].

Scanning electron microscopy (SEM) specimens of the CNFS/Ag NP composites were mounted on metal mounts with double-sided adhesive tape and coated with gold plasma to enhance conductivity using a plasma multi-coater PMC-5000 (Meiwafosis Co., Ltd., Tokyo, Japan). The surface morphology of coated samples was examined by JSM-6340 F microscope (JEOL, Tokyo, Japan) operated at $5 \mathrm{kV}$. The TEM image of CNFS/Ag NPs were carried out by cutting the composite sheet into very small pieces and then resuspending in $200 \mu \mathrm{l}$ distilled water; $5 \mu$ l of the resulting suspension was observed by TEM with the JEOL JEM-1010 microscope.

\section{Bactericidal activity of CNFS/Ag NPs}

A culture of E. coli strain DH5a (Takara Co., Kyoto, Japan) was stored at $-80^{\circ} \mathrm{C}$ in Luria-Bertani (LB) broth containing $50 \%$ sterile glycerol. Overnight cultures were prepared by growing a single $E$. coli colony overnight at $37^{\circ} \mathrm{C}$ in $5 \mathrm{ml}$ of LB medium. On the next day, $200 \mu \mathrm{l}$ of the overnight culture was inoculated into $2 \mathrm{ml}$ of LB medium and incubated at $37^{\circ} \mathrm{C}$ for $6 \mathrm{~h}$ or until the optical density at $600 \mathrm{~nm}\left(\mathrm{OD}_{600}\right)$ reached 0.260 . The E. coli culture then was diluted 4-fold with LB broth, and $30 \mu \mathrm{l}$ of the diluted suspension were spread on LB agar (ForMedium Ltd., Hunstanton, England). CNFS/Ag NPs and CNFS alone then were placed onto the surface of the inoculated agar plate, which was incubated at $37^{\circ} \mathrm{C}$ overnight. Growth inhibition zones around the sheets were measured on the subsequent day using a centimeter scale.
The experiment on $P$. aeruginosa was carried out using essentially the same technique as for E. coli. The P. aeruginosa strain ATCC 27853 (American Type Culture Collection (ATCC), Manassas, USA) was stored at $-80^{\circ} \mathrm{C}$ in Luria-Bertani (LB) broth containing 50\% sterile glycerol. The cell suspension of $P$. aeruginosa was prepared as follows: $20 \mu \mathrm{l}$ of stock suspension was plated onto Pseudomonas Isolation agar (Neogen Ltd. Michigan, USA) and incubated at $37^{\circ} \mathrm{C}$ for $18 \mathrm{~h}$. Colonies then were resuspended by placing $2 \mathrm{ml}$ of LB broth on the plate surface and gently shaking the plate by hand for few minutes. The resulting suspension was pipetted to a new tube for the next experiments (or stocked at $-80^{\circ} \mathrm{C}$ with glycerol). Following adjustment to $\mathrm{OD}_{600}$ of 0.26 , this suspension was diluted a further 4-fold, and $30 \mu \mathrm{l}$ was spread onto nutrient agar (Nissui Pharmaceutical CO., LTD, Tokyo, Japan). CNFS/Ag NPs and CNFS alone then were placed onto the surface of the inoculated agar plate, which was incubated at $37^{\circ} \mathrm{C}$ overnight. Growth inhibition zones around the sheets were measured on the subsequent day using a centimeter scale.

Forty $\mu \mathrm{l}$ of the diluted cultures of $E$. coli and $P$. aeruginosa were dropped onto each CNFS composite harboring immobilized Ag NPs at various concentrations (8.5, 3.8, 2.3 , and $0 \mu \mathrm{g} / 1 \mathrm{~cm}^{2}$ sheet $\left.(7.3 \pm 0.1 \mathrm{mg})\right)$. All of the sheets were incubated at $37^{\circ} \mathrm{C}$ for $1 \mathrm{~h}$, and each sheet then was immersed/washed in $1 \mathrm{ml} \mathrm{LB}$ medium. The resulting wash suspensions were subjected to 10 -fold serial dilutions, and $50 \mu \mathrm{l}$ samples of diluted suspensions were plated (to $90 \times 15 \mathrm{~mm}$ petri plates of LB agar (for $E$. coli) or nutrient agar (for $P$. aeruginosa)). Plates were incubated at $37^{\circ} \mathrm{C}$ for $24 \mathrm{~h}$, and viable cells were enumerated.

\section{Evaluation of the antiviral activity of CNFS /Ag NPs}

Antiviral activity of CNFS/Ag NPs was evaluated against H1N1 influenza A virus as described previously [17,30]. Fifty $\mu \mathrm{l}$ of viral suspension (about $10^{5} \mathrm{TCID}_{50} / \mathrm{ml}$ ) was added onto CNFS/Ag NPs consisting of various amounts of $\operatorname{Ag}$ NPs $(8.5,3.8,2.3$, and $0 \mu \mathrm{g})$ immobilized on $1 \mathrm{~cm}^{2}$ CNFS $(7.3 \pm 0.1 \mathrm{mg})$. The virus-inoculated composites were placed in an empty petri dish and incubated at room temperature for $1 \mathrm{~h}$ to facilitate the interaction between the viruses and the CNFS/Ag NPs. The sheets then were individually transferred to $1.5 \mathrm{ml}$ tubes, each of which received $450 \mu \mathrm{l}$ phosphate-buffered saline (PBS) and $1 \mathrm{~min}$ of vortexing. Following centrifugation at $6400 \mathrm{~g}$ for $5 \mathrm{~min}$, the supernatants were transferred to new tubes, then subjected to eleven 2 -fold serial dilutions in PBS. Fifty $\mu \mathrm{l}$ of each diluted supernatant was added to the individual wells of a 96-well plate containing MDCK cells. The samples were incubated at $37^{\circ} \mathrm{C}$ and $5 \% \mathrm{CO}_{2}$ for $1 \mathrm{~h}$ to allow virus adsorption to the cells. Aliquots of growth medium (50 $\mu \mathrm{l}$ DMEM medium containing $0.4 \%$ BSA and $5 \mu \mathrm{g} / \mathrm{ml}$ trypsin) were added to each well. After 
5 days of incubation, another $50 \mu \mathrm{l}$ of DMEM medium containing $0.4 \%$ BSA was added to each well. Seven days post-infection, surviving cells were fixed with methanol (200 $\mu \mathrm{l} /$ well, two times), and stained with $50 \mu \mathrm{l}$ of $5 \%$ Giemsa stain solution. Cells counts (stained (uninfected) and unstained (infected)) were determined, and viral titers (in $\mathrm{TCID}_{50} / \mathrm{ml}$ ) were calculated according to method of Reed and Muench $[17,30]$.

\section{Ultrathin sectioning of bacterial cells}

In order to understand the bactericidal activities of silver nanoparticles, ultrathin sectioning was carried out to observe ultrastructural changes in bacterial cells. Two $\mathrm{ml}$ of Ag NPs suspension $(6 \mu \mathrm{g} / \mathrm{ml})$ was placed on the surfaces of agar plates containing colonies of $E$.coli or $P$. aeruginosa. After $1 \mathrm{~h}$ the colonies were recovered and fixed overnight (minimum of $2 \mathrm{~h}$ ) at $4^{\circ} \mathrm{C}$ with $2 \%$ glutaraldehyde and $2 \%$ paraformaldehyde in $0.1 \mathrm{M}$ phosphate buffer, $\mathrm{pH}$ 7.4. The fixed samples were washed overnight (minimum of $2 \mathrm{~h}$ ) at $4^{\circ} \mathrm{C}$ in $0.1 \mathrm{M}$ phosphate buffer, then post-fixed for $2 \mathrm{~h}$ at $4^{\circ} \mathrm{C}$ in $1 \% \mathrm{OsO}_{4}$ in $0.1 \mathrm{M}$ phosphate buffer. The samples then were dehydrated by using a series of alcohol solutions at increasing concentration (50, 75, 95\% at $20 \mathrm{~min}$ each, followed by 2 passages in $100 \%$ ethanol for $30 \mathrm{~min}$ each). Samples were infiltrated at room temperature by immersion in propylene oxide $(2 \times 30 \mathrm{~min}), 1: 1$ mixture of propylene oxide and epoxy resin $(1 \mathrm{~h}), 1: 2$ mixture of propylene oxide and epoxy resin (overnight), and epoxy resin only (minimum $4 \mathrm{~h}$ ). The samples then were embedded with epoxy resin in a Beem capsule and polymerized in an oven at $37^{\circ} \mathrm{C} / 12 \mathrm{~h}$, $45^{\circ} \mathrm{C} / 24 \mathrm{~h}$, and $60^{\circ} \mathrm{C} / 48 \mathrm{~h}$. The polymerized samples were first semi-thin sectioned at $1.5 \mu \mathrm{m}$ with glass knives using UltraCut $\mathrm{S}$ and stained with Toluidine Blue. Ultrathin sections were obtained with an ultramicrotome (UltraCut S, Reichert) with ultrathin slices 60 to $90 \mathrm{~nm}$ in thickness. Ultrathin slices were recovered on a $3.0 \mathrm{~mm}$-diameter 200-mesh copper grid and stained with uranyl acetate for $20 \mathrm{~min}$ and lead acetate for $1 \mathrm{~min}$. The grids were examined by TEM (JEM-1010).

\section{Statistical analyses}

Statistical analyses were carried out using StatMate III, Macintosh Version (ATMS Co., Tokyo, Japan). Statistical significance was assumed when $\mathrm{p}<0.01$. Where relevant, values are provided as mean \pm SD.

\section{Abbreviations}

CNFSs: Chitin nanofibers sheets; CNFS/Ag NPs: CNFS-immobilized silver nanoparticles; TEM: Transmission electron microscopy; SEM: Scanning electron microscopy; UV-Vis: Visible-Ultraviolet spectrums.

\section{Competing interests}

The authors declare that they have no competing interests.

\section{Authors' contributions}

VQN designed the research, performed the experiments, and drafted the manuscript and the figures. MI and TM supervised and coordinated the study and approved the manuscript. TO and YMi supervised, guided and performed the viral study. JK assisted VQN and performed some parts of experiments. $\mathrm{HH}$ and $\mathrm{SN}$ guided the study and assisted to draft the manuscript and the figures. All authors read and approved the final manuscript.

\section{Acknowledgment}

The authors also thank Ms. Y Ichiki from Laboratory Center of National Defense Medical College for her help with the electron microscopy experiments.

\section{Author details}

${ }^{1}$ Faculty of System Design, Tokyo Metropolitan University, 6-6 Asahigaoka, Hino, Tokyo 191-0065, Japan. ${ }^{2}$ Research Institute, National Defense Medical College, 3-2 Namiki, Tokorozawa, Saitama 359-1324, Japan. ${ }^{3}$ Department of Oral and Maxillofacial Surgery, National Defense Medical College, 3-2 Namiki, Tokorozawa, Saitama 359-8513, Japan. ${ }^{4}$ Department of Global Infectious Diseases and Tropical Medicine, National Defense Medical College, 3-2 Namiki, Tokorozawa, Saitama 359-8513, Japan.

Received: 18 August 2014 Accepted: 4 November 2014

Published online: 03 December 2014

\section{References}

1. Ishihara M, Fujita M, Kishimoto S, Hattori H, Kanatani Y: Biological, Chemical, and Physical Compatibility of Chitosan and Biopharmaceuticals. In Chitosan-Based Systems for Biopharmaceuticals. Edited by Samento B, Neves JD. West Sussex, UK: John Wiley\&Sons, Ltd; 2012:93-107.

2. Muzzarelli RAA, Morganti P, Morganti G, Palombo P, Palombo M, Biagini G, Mattioli BM, Belmonte M, Giantomassi F, Orlandi F, Muzzarelli C: Chitin nanofibrils/chitosan glycolate composites as wound medicaments. Carbohydr Polym 2007, 70:274-284.

3. Ishihara M, Nakanishi K, Ono K, Sato M, Saito Y, Yura H, Matsui T, Hattori H, Uenoyama M, Kurita A: Photocrosslinkable chitosan as a dressing for wound occlusion and accelerator in healing process. Biomaterials 2002, 23(3):833-840.

4. Hattori H, Amano $Y$, Nogami $Y$, Takase B, Ishihara M: Hemostasis for severe hemorrhage with photocrosslinkable chitosan hydrogel and calcium alginate. Ann Biomed Engin 2010, 38(12):3724-3732.

5. Kiyozumi T, Kanatani Y, Ishihara M, Saitoh D, Shimizu J, Yura H, Suzuki S, Okada Y, Kikuchi M: Medium (DMEM/F12)-containing chitosan hydrogel as adhesive and dressing in autologous skin grafts and accelerator in the healing process. J Biomed Mater Res 2006, 79B(1):129-136.

6. Ishihara M, Fujita M, Obara K, Hattori H, Nakamura S, Nambu M, Kiyosawa T, Maehara T: Controlled releases of FGF-2 and paclitaxel from chitosan hydrogels and their subsequent effects on wound repair, angiogenesis, and tumor growth. Curr Drug Deliv 2006, 3(4):351-358.

7. Masuoka K, Ishihara M, Asazuma T, Hattori H, Matsui T, Takase B, Kanatani Y, Fujita M, Saito Y, Yura H, Fujikawa K, Nemoto N: Interaction of chitosan with fibroblast growth factor- 2 and its protection from inactivation. Biomaterials 2005, 26(16):3277-3284.

8. Jayakumar R, Prabaharan M, Nair SV, Tamura H: Novel chitin and chitosan nanofibers in biomedical applications. Biotechnol Advances 2010, 28:142-150.

9. Morganti P, Morganti G: Chitin nanofibrils for advanced cosmeceuticals. Clinic Dermatol 2008, 26(4):334-340.

10. Dutta AK, Kawamoto N, Sugino G, Izawa H, Morimoto M, Saimoto H, Ifuku S: Simple preparation of chitosan nanofibers from dry chitosan powder by the star burst system. Carbohydro Polym 2013, 98:1198-1202.

11. Lee M-Y, Park JM, Yang J-W: Micro precipitation of lead on the surface of crab shell particles. Process Biochem 1997, 32(8):671-677.

12. Nguyen $V Q$, Ishihara $M$, Nakamura $S$, Hattori H, Ono T, Miyahira $Y$, Matsui $T$ : Interaction of Silver Nanoparticles and Chitin Powder with Different Sizes and Surface Structures: The Correlation with Antimicrobial Activities. J Nanomater 2013, 2013:9. art no.467534.

13. Min SK, Lee SC, Hong SD, Chung CP, Park WH, Min BM: The effect of a laminin5-derived peptide coated onto chitin microfibers on re-epithelialization in early-stage wound healing. Biomaterials 2010, 31(17):4725-4730. 
14. Pillai CKS, Sharma CP: Electrospinning of Chitin and Chitosan Nanofibres. Trends Biomater Artif Organ 2009, 22(3):179-201.

15. Nguyen VQ, Ishihara M, Mori Y, Nakamura S, Kishimoto S, Hattori H, Fujita M, Kanatani Y, Ono T, Miyahira Y, Matsui T: Preparation of Size-Controlled Silver Nanoparticles and Chitin-Based Composites and Their Antimicrobial Activities. J Nanomater 2013, 2013:7. art no. 693486.

16. Nguyen VQ, Ishihara M, Mori Y, Nakamura S, Kishimoto S, Fujita M, Hattori H, Kanatani Y, Ono T, Miyahira Y, Matsui T: Preparation of size-controlled silver nanoparticles and chitosan-based composites and their anti-microbial activities. Biomed Mater Eng 2013, 23(6):473-483.

17. Mori Y, Ono T, Miyahira Y, Nguyen VQ, Matsui T, Ishihara M: Antiviral activity of silver nanoparticle/chitosan composites against H1N1 influenza A virus. Nanoscale Res Lett 2013, 8(1):88-93.

18. Tran HV, Tran LD, Ba CT, Vu HD, Nguyen TN, Pham DG, Nguyen PX: Synthesis, characterization, antibacterial and antiproliferative activities of monodisperse chitosan-based silver nanoparticles. Colloids and Surfaces $A$ : Physicochem Engineer Aspects 2010, 360(1-3):32-40.

19. Sotiriou GA, Pratsinis SE: Antibacterial Activity of Nanosilver lons and Particles. Environ Sci Technol 2010, 44(14):5649-5654.

20. Yamanaka $M$, Hara K, Kudo J: Bactericidal actions of a silver ion solution on Escherichia coli, studied by energy-filtering transmission electron microscopy and proteomic analysis. Appl Environ Microbiol 2005, 71(11):7589-7593.

21. Sondi I, Salopek-Sondi B: Silver nanoparticles as antimicrobial agent: a case study on E. coli as a model for Gram-negative bacteria. J Colloid Interface Sci 2004, 275(1):177-182.

22. Kim S-H, Lee H-S, Ryu D-S, Choi S-J, Lee D-S: Antibacterial activity of silver-nanoparticles against Staphylococus and Escherichia coli. Korean J Microbiol Biotechnol 2011, 39:770-785.

23. Pellieux C, Dewilde A, Pierlot C, Aubry J-M: Bactericidal and virucidal activities of singlet oxygen generated by thermolysis of naphthalene endoperoxides. Methods Enzymol 2000, 319:197-207.

24. Abdelgawad AM, Hudson SM, Rojas OJ: Antimicrobial wound dressing nanofiber mats from multicomponent (chitosan/silver-NPs/polyvinyl alcohol) systems. Carbohydr Polym 2014, 100:166-178.

25. AshaRani PV, Low Kah Mun G, Hande MP, Valiyaveettil S: Cytotoxicity and genotoxicity of silver nanoparticles in human cells. ACS Nano 2009, 3(2):279-290.

26. De Lima R, Seabra AB, Duran N: Silver nanoparticles: a brief review of cytotoxicity and genotoxicity of chemically and biogenically synthesized nanoparticles. J Appl Toxicol 2012, 32(11):867-879.

27. Hackenberg S, Scherzed A, Kessler M, Hummel S, Technau A, Froelich K, Ginzkey C, Koehler C, Hagen R, Kleinsasser N: Silver nanoparticles: evaluation of DNA damage, toxicity and functional impairment in human mesenchymal stem cells. Toxicol Let 2011, 201(1):27-33.

28. Ong S-Y, Wu J, Moochhala SM, Tan M-H, Lu J: Development of a chitosanbased wound dressing with improved hemostatic and antimicrobial properties. Biomaterials 2008, 29(32):4323-4332.

29. Mori Y, Tagawa T, Fujita M, Kuno T, Suzuki S, Matsui T, Ishihara M: Simple and environmentally friendly preparation and size control of silver nanoparticles using an inhomogeneous system with silver-containing glass powder. J Nanopart Res 2011, 13(7):2799-2806.

30. Ito I, Osaki T, Ifuku S, Saimoto H, Takamori Y, Kurozumi S, Imagawa T, Azuma K, Tsuka T, Okamoto Y, Minami S: Evaluation of the effects of chitin nanofibrils on skin function using skin models. Carbohydr Polym 2014, 101:464-470.

31. Azuma K, Osaki T, Wakuda T, Ifuku S, Saimoto H, Tsuka T, Imagawa T, Okamoto $Y$, Minami S: Beneficial and preventive effect of chitin nanofibrils in a dextran sulfate sodium-induced acute ulcerative colitis model. Carbohydr Polym 2012, 87:1399-1403.

32. Elechiquerra J, Burt JL, Morones JR, Camacho-Bragado A, Gao X, Lara HH, Yacaman M: Interaction of silver nanoparticles with HIV-1. J Nanobiotechnol 2005, 3(6):1-10.

33. Lu L, Sun RW, Chen R, Hui CK, Ho CM, Luk JM, Lau GK, Che CM: Silver nanoparticles inhibit hepatitis B virus replication. Antivir Ther 2008 13(2):253-262.

\section{doi:10.1186/s12951-014-0049-1}

Cite this article as: Nguyen et al:: Development of antimicrobial biomaterials produced from chitin-nanofiber sheet/silver nanoparticle composites. Journal of Nanobiotechnology 2014 12:49.

\section{Submit your next manuscript to BioMed Central and take full advantage of:}

- Convenient online submission

- Thorough peer review

- No space constraints or color figure charges

- Immediate publication on acceptance

- Inclusion in PubMed, CAS, Scopus and Google Scholar

- Research which is freely available for redistribution 